\title{
Programa de reestruturação e contratualização dos hospitais filantrópicos no SUS: uma avaliação do eixo de financiamento
}

\author{
César Augusto Neves \\ Instituto Federal de Educação, Ciência e Tecnologia do Sudeste de Minas Gerais, \\ Campus São João Del-Rei (IFET - Campus São João Del-Rei) \\ Patrícia Aparecida Ferreira \\ Universidade Federal de Lavras (UFLA) \\ Dany Flávio Tonelli \\ Universidade Federal de Lavras (UFLA)
}

A partir de um estudo em dois estabelecimentos de saúde contratualizados sob a ótica dos implementadores, este artigo procurou avaliar o programa de modo a identificar impactos, avanços, lacunas e problemas no eixo do financiamento e comparar os valores financeiros que os hospitais receberiam adotando os modelos de contratação antigo (por produção) e atual (através de metas e incentivos). Para a coleta de dados foram realizadas entrevistas semiestruturadas em profundidade com os membros da comissão de acompanhamento do contrato. Também foram investigados documentos e coletados dados quantitativos/financeiros nas bases de dados do Datasus. Os principais resultados foram: houve ampla utilização de contratos de metas; observou-se o incremento do financiamento, mas de forma ainda insatisfatória para sanar os problemas financeiros das instituições; os limites orçamentários do governo local ainda impedem a execução integral do contrato; e a existência conjunta de dois tipos de financiamento estimula a priorização de determinados tipos de atendimento.

Palavras-chave: Sistema Único de Saúde, financiamento - administração hospitalar, avaliação de políticas públicas

[Artigo recebido em 29 de agosto de 2017. Aprovado em 16 de agosto de 2018.] 
Programa de reestructuración y contratación de los hospitales filantrópicos en el SUS: una evaluación del eje de la financiación

A partir de un estudio en dos establecimientos de salud contratados bajo la óptica de los implementadores, este artículo intentó evaluar el programa de modo a identificar impactos, avances, lagunas y problemas en el eje de la financiación y comparar los valores financieros que los hospitales recibirían adoptando los modelos de contratación antiguo (por producción) y actual (a través de metas e incentivos). Para la recolección de datos se realizaron entrevistas semiestructuradas en profundidad con los miembros de la comisión de acompañamiento del contrato. También se investigaron documentos y se recolectaron datos cuantitativos/financieros en las bases de datos de Datasus. Los principales resultados fueron: hubo amplia utilización de contratos de metas; se observó el incremento de la financiación, pero de manera aún insatisfactoria para sanar los problemas financieros de las instituciones; los límites presupuestarios del gobierno local todavía impiden la ejecución integral del contrato; y la existencia conjunta de dos tipos de financiación estimula la priorización de determinados tipos de atención.

Palabras-clave: Sistema Único de Salud, financiamiento - administración hospitalaria, evaluación de políticas públicas

The restructuring and contracting non-profit hospitals programme within the SUS: an assessment of financing dimension

Based on a study of two contracted healthcare providers from the perspective of the implementers, this paper aims to evaluate the program in order to identify impacts, achievements, gaps and problems in the funding axis and to compare the financial values that hospitals would receive by adopting the contracting models traditional (by production) and current (through goals and incentives). For data collection, semi-structured interviews were conducted in depth with the members of the contract monitoring committee. We also investigated documents and collected quantitative/financial data in DATASUS databases. The main results were: there was a wide use of target contracts; there was an increase in funding, but still unsatisfactory to remedy the financial problems of the institutions; the local government budget limits still prevent the full execution of the contract; and the joint existence of two types of financing stimulates the prioritization of certain types of service.

Key words: Unified Health System, financing - hospital administration, evaluation of public policies 


\section{Introdução}

A Constituição Federal Brasileira de 1988 instituiu a saúde pública como direito de todos e dever do Estado. O que antes era uma prestação de serviços fragmentada e excludente passou a integrar uma estrutura única e descentralizada, de assistência integral e universal. Em um país extenso e populoso como o Brasil, garantir esse direito a todos, gerir e financiar todas estas ações exige grandes esforços e dispêndios. Nestes trinta anos de existência do Sistema Único de Saúde (SUS) instituíram-se diversas outras leis e normativas que constantemente vêm aprimorando-o, mas a qualidade do atendimento ainda é questionável e o crônico problema do financiamento está longe de uma solução (QUINTELLA, 2007; SILVA, 1996; BARBOSA; ELIAS, 2010).

A defesa dos princípios constitucionais da universalidade e da integralidade do serviço de saúde para a construção de uma cidadania plena e efetiva contrasta com a problemática do financiamento. O processo de construção e aprimoramento do SUS desenvolve-se sobre esse "cabo de guerra", opondo a visão sistêmica, integral e integradora à visão economicista, contábil-financeira, que busca a racionalidade de gastos como forma de equilíbrio (QUINTELLA, 2007).

O Estado é historicamente frágil na prestação de serviços de saúde, em especial na entrega de serviços hospitalares e de diagnóstico, e nunca conseguiu atender a toda a demanda por assistência (QUINTELLA, 2007). Como alterativa a essa deficiência de estrutura, a Constituição Federal permite, em seu artigo 199, que a iniciativa privada possa participar dessa prestação de serviços de forma complementar, com prioridade para as instituições filantrópicas e as sem fins lucrativos. É neste cenário que se inserem os hospitais filantrópicos. Com origem ainda no período da colonização do país, essas organizações sempre tiveram como objetivo atender às pessoas carentes e necessitadas de serviços básicos de saúde que o Estado não garantia. Segundo dados do Cadastro Nacional de Estabelecimentos de Saúde, os hospitais considerados filantrópicos correspondem a $1 / 4$ das unidades hospitalares e da disponibilidade de leitos do SUS (BARBOSA et al., 2003; 2004).

O setor hospitalar filantrópico possui um papel estratégico para o SUS. Muitas vezes é o único prestador de serviços hospitalares em municípios do interior, e também como prestador de serviços de maior complexidade hospitalar em capitais e cidades de maior porte (BARBOSA et al., 2003). Considerando a fragilidade econômica e gerencial observável em parte significativa deste segmento - o que ameaça a sobrevivência do sistema - é emergente a necessidade de mudanças na atenção hospitalar brasileira visando a melhorias na assistência, na gestão e no financiamento (BARBOSA et al., 2004). 
Na parceria que se dá entre as duas partes é dever da unidade hospitalar prestar os serviços contratados e administrar as despesas oriundas destes, enquanto cabe ao Estado regular e financiar essas ações. Essa relação contratual normalmente se resumia em transferências financeiras para pagar procedimentos ambulatoriais e/ ou hospitalares. A lógica de pagamento por produção foi quebrada com a criação, em 2005, do Programa de Reestruturação e Contratualização dos Hospitais Filantrópicos no Sistema Único de Saúde (Portaria GM/MS no 1.721/2005), nos moldes do que foi adotado junto aos hospitais de ensino e aos de pequeno porte desde 2003 (Couttolenc; LA Forgia, 2009; CAVAlCANTE, 2012).

O objetivo do programa, conforme dispõe a Portaria GM/MS no 1.721/2005, é apresentar alternativas para melhorar a gestão e os resultados dos hospitais, buscando o saneamento das finanças, a superação da crise assistencial e a inserção no sistema locorregional de saúde, observando as demais políticas e princípios do Sistema Único de Saúde (BRASIL, 2005).

Assim como em todo o sistema de saúde, o financiamento é uma das principais fontes de problemas dessa política pública, e acaba influenciando na implementação e nos resultados dos demais eixos de ação, tais como assistência e gestão. Para os hospitais, por exemplo, o subfinanciamento é incessantemente debatido entre as principais instituições representativas das partes. Essa política de subfinanciamento, transferindo aos hospitais valores abaixo dos custos necessários para a prestação dos serviços contratados, gera preocupantes crises financeiras nesses estabelecimentos (COUTTOLENC; LA FORGIA, 2009).

Assim, insere-se o problema que orienta a realização deste trabalho: como tem sido implementado o Programa de Reestruturação e Contratualização dos Hospitais Filantrópicos no SUS no eixo do financiamento? A partir de um estudo em dois estabelecimentos de saúde contratualizados sob a ótica dos implementadores, este artigo procura avaliar o programa de modo a identificar impactos, avanços, lacunas e problemas no eixo do financiamento e comparar os valores financeiros que os hospitais receberiam adotando os modelos de contratação antigo (por produção) e atual (através de metas e incentivos).

O trabalho apresenta um recorte teórico sobre o conceito de políticas públicas e avaliação, bem como uma contextualização do Programa de Reestruturação e Contratualização dos Hospitais Filantrópicos. Do mesmo modo, são apresentados os procedimentos metodológicos utilizados para realização da pesquisa, bem como os resultados encontrados e, por fim, as considerações finais. 


\section{Fundamentação teórica}

\section{Políticas Públicas e Avaliação}

As políticas públicas são geralmente definidas como a ação concreta do Estado, ou o "Estado em ação". Entretanto, há ainda muitas discordâncias de conceitos e explicações entre os grandes estudiosos da área e nenhuma definição consensual (SouZA, 2006). De forma mais abrangente, considera-se neste trabalho a definição de políticas públicas proposta por Fonseca (2013), que as entende como um processo de decisão política que:

[...] se materializa em objetivos com resultados esperáveis, normalmente vinculados à transformação de uma dada realidade, com vetores distintos, e que envolvem: a) técnicos estatais e não governamentais, burocratas e políticos (tomadores de decisão); b) atores distintos (com "recursos de poder" assimétricos), cenários e conjunturas (por vezes voláteis); c) capacidade e viabilidade de o Estado disponibilizar recursos orçamentários, humanos, legais e logísticos; d) mecanismos de mensuração dos resultados (FONSECA, 2013, p. 405).

Um dos principais e mais populares modelos de explicação e análise de políticas públicas difundidos é o denominado de "Ciclo de Políticas Públicas", de Laswell e Jones (1936), por meio do qual se entende a ação governamental como processual, onde há um início e um fim bem delimitados em etapas de formulação, implementação e avaliação (SouZA, 2006).

A visão fragmentada do ciclo de política pública em etapas tem sido objeto de muitas críticas. Normalmente as etapas ocorrem ao mesmo tempo ou em ordem diferente e, especializar a análise em apenas uma das etapas acaba limitando a visão da política em seu conjunto. Por outro lado, Fonseca (2013) destaca que o modelo de ciclo de políticas públicas pode ser utilizado para fins mais pedagógicos do que propriamente reais, uma vez que a realidade não apenas é mais complexa do que fazem supor essas etapas, como também mais "confusa".

Considerando a clareza e facilidade que o modelo de ciclo de políticas públicas proporciona aos estudiosos e analistas de políticas públicas na formulação de suas teorias e avaliações (FREY, 2000), a Tabela 1 apresenta as etapas do ciclo e suas particularidades. 
Tabela 1 - Ciclo de políticas públicas: atividades e atores principais

\begin{tabular}{|c|c|c|c|c|c|}
\hline \multicolumn{6}{|c|}{ CICLO DE POLÍTICAS PÚBLICAS } \\
\hline & FASE I & FASE II & FASE III & FASE IV & FASE V \\
\hline FASE & $\begin{array}{l}\text { Identificação e } \\
\text { institucionali- } \\
\text { zação de um } \\
\text { problema }\end{array}$ & $\begin{array}{l}\text { Formulação } \\
\text { de soluções e } \\
\text { ações }\end{array}$ & $\begin{array}{l}\text { Tomada de } \\
\text { decisões }\end{array}$ & $\begin{array}{l}\text { Imple- } \\
\text { mentação }\end{array}$ & Avaliação \\
\hline ATIVIDADES & $\begin{array}{l}\text { Valores, aconteci- } \\
\text { mentos, interes- } \\
\text { ses, demandas e } \\
\text { agenda pública. }\end{array}$ & $\begin{array}{l}\text { Elaboração } \\
\text { e valoração } \\
\text { de respostas, } \\
\text { seleção de } \\
\text { critérios. }\end{array}$ & $\begin{array}{c}\text { Encontrar } \\
\text { uma coalizão } \\
\text { majoritária, } \\
\text { legitimação. }\end{array}$ & $\begin{array}{l}\text { Execução, } \\
\text { gestão, } \\
\text { efeitos } \\
\text { concretos. }\end{array}$ & $\begin{array}{l}\text { Reações, } \\
\text { juízo sobre } \\
\text { os efeitos, } \\
\text { medição, } \\
\text { valoração, } \\
\text { propostas de } \\
\text { reajustes. }\end{array}$ \\
\hline ATORES & $\begin{array}{c}\text { Partidos, } \\
\text { movimentos } \\
\text { sociais, grêmios, } \\
\text { mídia, políticos, } \\
\text { administração } \\
\text { pública, ONGs, } \\
\text { etc. }\end{array}$ & $\begin{array}{c}\text { Congresso } \\
\text { e câmaras } \\
\text { legislativas, } \\
\text { administração } \\
\text { pública, } \\
\text { grêmios, } \\
\text { organizações } \\
\text { políticas e } \\
\text { sociais, ONGs, } \\
\text { etc. }\end{array}$ & $\begin{array}{c}\text { Congresso } \\
\text { e câmaras } \\
\text { legislativas, } \\
\text { presidente, } \\
\text { ministros, } \\
\text { governadores, } \\
\text { prefeitos. }\end{array}$ & $\begin{array}{l}\text { Adminis- } \\
\text { tração } \\
\text { pública, } \\
\text { ONGs, } \\
\text { empresas } \\
\text { privadas, } \\
\text { etc. }\end{array}$ & $\begin{array}{c}\text { Mídia, } \\
\text { acadêmicos, } \\
\text { administração } \\
\text { pública, } \\
\text { afetados, } \\
\text { responsáveis } \\
\text { políticos, } \\
\text { grêmios, } \\
\text { organizações } \\
\text { políticas e } \\
\text { sociais, ONGs, } \\
\text { etc. }\end{array}$ \\
\hline
\end{tabular}

Fonte: adaptado de Deubel, 2008

Vale destacar que a etapa da avaliação se constitui de um processo complexo que encontra diversas resistências para sua efetiva execução. Após ou durante a implementação da política pública, pesquisadores internos ou externos podem verificar se os objetivos iniciais foram atingidos, como o processo foi executado e se os insumos foram suficientes e devidamente utilizados. Mais importante ainda é avaliar o impacto que essa ação governamental específica causou nos beneficiários e para a melhoria da sociedade como um todo (MATTOS; BAPTISTA, 2015; COSTA; CASTANHAR, 2003).

As últimas décadas foram de grandes transformações na relação Estado, mercado e sociedade. A emergência dos movimentos sociais na década de 1970 (democratização) e as crescentes demandas dos cidadãos por políticas públicas exigiram redimensionamento, transparência e maior racionalidade do gasto público e do rendimento dos recursos aplicados, garantindo a eficiência, a eficácia e a efetividade em suas ações (ALMEIDA; PAULA, 2014). A avaliação encaixa-se 
convenientemente nesse novo papel do Estado, sendo uma forma de medir, acompanhar e avaliar o êxito das políticas públicas, de modo a representar um:

(...) instrumento fundamental para se alcançar melhores resultados e proporcionar uma melhor utilização e controle dos recursos nele aplicados, além de fornecer aos formuladores de políticas sociais e aos gestores de programas dados importantes para o desenho de políticas mais consistentes e para gestão pública mais eficaz (COSTA; CASTANHAR, 2003, p. 2).

A avaliação na concepção etimológica do termo significa:

(...) valor, esforço de apreciar efeitos reais, determinando o que é bom ou ruim. Trata-se de um julgamento valorativo, portanto não é um ato neutro, nem exterior às relações de poder, mas um ato eminentemente político que integra o contexto de um programa público, exigindo postura de objetividade e de independência, sendo por natureza uma atividade interdisciplinar (SILVA, 2001, p. 48).

Há diversas definições e delimitações da avaliação de políticas públicas. Em sua maioria tratam de abordagens lineares e estandardizadas, com pouco espaço para a crítica à própria política, desde a sua formulação e, menos ainda, aos princípios nos quais se alicerça. Para além do mero controle de gastos, emergem abordagens da avaliação como um instrumento de controle social, enfatizando, em seu processo, a análise do contexto social, econômico, político, cultural e organizacional (estrutura, dinâmica, relações de poder, interesses e valores) (ALMEIDA; PAULA, 2014).

A definição de bom ou ruim, êxito ou fracasso, pode partir de um julgamento subjetivo e conjuntural, envolvendo concepções ideológicas, métodos e enfoques diversos para uma mesma realidade (SILVA, 2001). Dessa forma, Arretche (2001) considera importante diferenciar os focos de avaliação das políticas públicas, pois cada olhar direcionará a avaliação para uma parte específica da política. Ela apresenta três dimensões da avaliação de políticas púbicas: análise de políticas públicas (avaliação das estruturas e instituições, dos processos e dos conteúdos); avaliação política da política (atribuição de valor aos resultados alcançados, a partir de princípios como igualdade, democracia e cidadania); e avaliação de políticas públicas (a avaliação como compromisso do Estado em relação aos cidadãos, visando produzir conhecimento teórico-metodológico, novas práticas de transformação das políticas e transparência das ações públicas).

Praticar uma avaliação a partir de perspectivas interdisciplinares, integrando as três dimensões citadas, seria o ideal, mas também é de um grande desafio. Uma proposta que vise superar essa limitação precisa apresentar análises e resultados 
amplos, detalhados e densos. Seria necessário também interpretar os significados culturais, ou seja, os significados da política para aqueles que as formulam, as executam e as vivenciam, buscando compreender por que as políticas funcionam ou falham e identificar as divergências e similitudes entre o que é formulado como política e como essa política se realiza na prática (ALMEIDA; PAULA, 2014).

Diante das limitações práticas a esta pesquisa, adota-se uma avaliação restrita do Programa de Restruturação e Contratualização dos Hospitais Filantrópicos no SUS, pois não foram incorporadas todas as dimensões apresentadas por Arretche (2001). Utilizou-se do modelo de Avaliação de Processo apresentado por Costa e Castanhar (2003), que visa: (i) investigar como o programa funciona (etapas, mecanismos, processos e conexões); (ii) detectar defeitos na elaboração dos procedimentos, acompanhar e avaliar a execução dos procedimentos de implantação dos programas; (iii) identificar barreiras e obstáculos à sua implementação; e (iv) gerar dados para sua reprogramação, por meio do registro de intercorrências e de atividades. Essa avaliação se realiza concomitantemente ao desenvolvimento do programa, portanto, o uso adequado das informações produzidas permite incorporar mudanças ao seu conteúdo (COSTA; CASTANHAR, 2003). É importante destacar também que tal avaliação parte do ponto de vista dos implementadores da política pública entrevistados nesta pesquisa, de acordo com os procedimentos apresentados na metodologia, com enfoque em um eixo específico do programa, a ser detalhado a seguir.

\section{O Programa de Reestruturação e Contratualização dos Hospitais Filantrópicos no SUS}

A história da relação público-privada através das instituições filantrópicas na área dos direitos sociais, principalmente da saúde, é longa, mas as principais características tendem a permanecer intactas. Os tradicionais instrumentos, tais como subvenção, isenção, utilidade pública, certificado de filantropia, contribuições, taxas e impostos são ainda hoje amplamente utilizados. Temos, contudo, maior formalidade e transparência nessas parcerias, mas pouco se avançou com relação à consagração dos direitos sociais e da universalização da cidadania. Tal configuração apenas reproduz ainda mais a pobreza e a desigualdade social na sociedade brasileira, além de reiterar a dependência de ajuda e de neutralizar demandas e reivindicações (MESTRINER, 2008).

O Estado reconhece esses direitos e assume a responsabilidade apenas com a Constituição Federal de 1988, apresentando seu comprometimento, introduzindo instrumentos de participação social e estabelecendo orçamento próprio para as políticas sociais. Contudo, mantém-se na implementação dessas políticas a 
parceria com o setor privado, através de contratos, investimentos, subvenções e desonerações fiscais, em vez do Estado assumir integralmente a responsabilidade pelas necessidades da população. "Estabelece-se nesta área uma complexa relação, que acaba escamoteando o dever do Estado e subordinando a atenção à benesse do setor privado" (MESTRINER, 2008, p. 18).

Em seu art. 199, a Constituição Federal define que a iniciativa privada possa participar da prestação de serviços de saúde pública de forma complementar, tendo prioridade as instituições filantrópicas e as sem fins lucrativos. Considerando que o histórico da saúde pública brasileira demonstra sua faceta excludente e segmentadora, o papel das instituições filantrópicas originalmente era o de atender a parcela da população que não tinha acesso às políticas governamentais de saúde. Com a Constituição de 1988 tem-se uma profissionalização dessa relação Estadoterceiro setor, exigindo planejamento e organização para inserir o segmento no sistema e integrá-lo às demais políticas e princípios do SUS (MESTRINER, 2008).

A presença do atendimento hospitalar como um dos elementos base da política pública de saúde exige uma atenção especial do Estado, através de metas e estratégias de consolidação da qualidade da assistência e da gestão desses estabelecimentos, assim como na preocupação com a sua sustentabilidade econômica. Os hospitais filantrópicos são parte importante desse segmento assistencial, representando 1/4 dos hospitais do país e sendo, geralmente, a única referência nesses atendimentos nas cidades de pequeno e médio porte (BARBOSA et al., 2003).

O Programa de Reestruturação e Contratualização dos Hospitais Filantrópicos no SUS, criado em 2005, é um importante marco nessa tentativa, e visa à melhoria da assistência, da gestão e do financiamento nesses estabelecimentos de saúde através da mudança da forma de pagamento (do pagamento feito a cada procedimento realizado para o pagamento global vinculado à produtividade e ao cumprimento de metas de qualidade).

Além disso, o programa tem por objetivos: (i) assegurar uma perspectiva sistêmica de rede, a integralidade da atenção e o alinhamento com as políticas prioritárias do SUS; (ii) facilitar e dinamizar os processos de avaliação, controle e regulação dos serviços ofertados; (iii) promover maior transparência na relação com o gestor local do SUS; (iv) ampliar os mecanismos de participação e controle social; (v) promover maior comprometimento dos profissionais da instituição; (vi) incentivar o uso racional dos recursos e a incorporação de tecnologias da informação; (vii) incentivar a formação de equipes multiprofissionais e da horizontalidade da organização do trabalho; promover, através de indicadores, a segurança dos pacientes, identificando-os corretamente, melhorando a comunicação entre os profissionais de saúde, controlando melhor a prescrição, uso e administração de 
medicamentos e estabelecendo processos mais exigentes de higienização para evitar infecções; e (viii) possibilitar o questionamento e enfrentamento dos arranjos de poder institucional (CAVALCANTE, 2012).

A Portaria no 1.721/05, que criou o programa, foi revogada e aprimorada pela Portaria no 3.410/13. Essa alteração na norma foi necessária para encaixar o programa na Política Nacional de Atenção Hospitalar, criada em 2013, que prevê uma melhoria no financiamento hospitalar e na busca pela qualidade dessa assistência. A Política Nacional de Atenção Hospitalar estabeleceu as diretrizes para a organização do componente hospitalar da Rede de Atenção à Saúde, focando na assistência, na gestão, na formação, no desenvolvimento e gestão da força de trabalho, no financiamento, na contratualização e nas responsabilidades de cada esfera de gestão. Está também interligada às Políticas Nacionais de Regulação, de Atenção Básica, de Atenção à Urgência, de Humanização, dentre outras (BRASIL, 2013a).

A Contratualização como um mecanismo de planejamento, avaliação, controle e regulação proposto por esse programa estabelece metas quantitativas e qualitativas em dois eixos - assistência e gestão - rompendo então com a lógica de pagamento por produção (BRASIL, 2005; 2013b; QuINTELLA, 2007; CAVALCANTE, 2012). As metas quantitativas referem-se à quantidade de procedimentos realizados pelo hospital no período avaliado. As metas qualitativas enquadram desde a redução da mortalidade ou infecção hospitalar até a participação de funcionários do hospital em cursos de gestão. O percentual referente às metas qualitativas aumentaria gradativamente a cada período avaliado até atingir $50 \%$ do valor a ser recebido. Os recursos financeiros, portanto, vincular-se-iam cada vez mais ao cumprimento de metas de qualidade e desempenho, e seriam menos influenciados pela quantidade de serviços prestados (Quintella, 2007; CAVALCANTE, 2012).

Para auxiliar nesse processo, o Ministério da Saúde instituiu o IAC - Incentivo de Adesão à Contratualização, substituído pelo IGH - Incentivo à Qualificação da Gestão Hospitalar, através da Portaria no 3.410/13. Trata-se de um recurso extra à produção dessas unidades que tem como função estimular o investimento em qualificação profissional e em melhorias nos processos administrativos, sem prejuízo às causas assistenciais. Destina-se a cada hospital filantrópico contratualizado a quantia referente a $50 \%$ do valor contratado para os procedimentos de média complexidade (BRASIL, 2013b).

A lógica do pagamento por produção, como dito anteriormente, dá espaço à orçamentação global mista, conforme estabelecido pela portaria que cria o programa (2005) e distribuída da seguinte forma: 
a. Parcela pós-fixada: continua nos mesmos moldes anteriores, pagando-se por produção os serviços considerados de alta complexidade ou financiados pelo FAEC - Fundo de Ações Estratégicas e de Compensação, além de políticas prioritárias ou especiais instituídas pelos governos federal ou estadual (Rede de Urgência e Emergência, Campanha de Cirurgias Eletivas, dentre outros);

b. Parcela pré-fixada: passa a ser formada pela média da produção na média complexidade em um determinado período, além dos incentivos a que tem direito a instituição (IGH, Integrasus). Esses valores são revistos apenas quando há alguma alteração no nível de produção ou nas quantidades pactuadas e estão atrelados ao cumprimento de metas.

Quando os hospitais não conseguem cumprir alguma das metas observa-se um desconto proporcional no valor devido (média dos últimos doze meses). Os incentivos não sofrem descontos. Tem-se assim uma lógica de penalização pelo descumprimento de metas, em vez de um sistema de incentivo ao cumprimento destas (BRASIL, 2005).

A tabela de preços adotada pelo Ministério da Saúde passa a ser apenas uma referência, considerando que o pagamento não estará diretamente vinculado a ela. Utiliza-se da tabela para a formação das parcelas a serem pagas e na repactuação das metas, mas durante a execução do contrato são as metas físicas e de qualidade que determinam o montante real a ser recebido pela prestação dos serviços (BRASIL, 2005; 2013b).

Para o sucesso desse programa, surge a necessidade de estabelecer um processo dinâmico e sistêmico de acompanhamento e avaliação. É para esses fins que se prevê a constituição das comissões permanentes de acompanhamento de contratos. Esses grupos, formados por representantes do órgão gestor do SUS municipal/ estadual, dos governos municipais abrangidos, dos hospitais e de representantes da sociedade (Conselho de Saúde), passam a ser a peça chave de todo o processo, pois será por meio de suas reuniões que as metas serão traçadas, o papel do hospital na rede será definido, as necessidades de saúde da população serão negociadas e os recursos financeiros serão estabelecidos. Todos os atores devem estar em sintonia e buscando um objetivo comum (BRASIL, 2005; 2013b).

Essa antecipação e conhecimento prévio dos valores a serem recebidos pela instituição permitem um melhor planejamento orçamentário e de fluxo de caixa. Contudo, a contrapartida dos hospitais pelos recursos recebidos passa a ser constituída em dois eixos, acrescentando as metas de gestão e de melhoria na assistência à tradicional prestação de serviços. Nesse programa há uma inovação, representada pela quebra da relação procedimento versus pagamento. Nos moldes anteriores não havia incentivo à reestruturação hospitalar, nem o incentivo à 
qualificação profissional, à reformulação de processos e à renovação tecnológica (QUINTELLA, 2007).

Contudo, estas mudanças não são simples e imediatamente aplicáveis, como se pode supor e, normalmente, quem mais sente o impacto são os hospitais contratados. Enquanto os demais atores apenas participam do levantamento de demandas e a avaliação dos resultados, cabem aos hospitais toda a adaptação a essa nova realidade. É complexa, por exemplo, a desvinculação da produção com o valor recebido. Boa parte dos profissionais que cuidarão dos pacientes diretamente, como os médicos e os fisioterapeutas, são autônomos, ou seja, prestam serviços ao hospital e seus rendimentos continuam sendo por produção. Trata-se de um novo processo gerencial árduo não apenas para administrar e direcionar os recursos, mas também para cumprir as metas qualitativas, considerando que os contratos ou acordos com esses profissionais são restritos às questões quantitativas. É um conflito a ser administrado e que não é compartilhado com os outros atores da comissão de acompanhamento (LIMA; RIVERA, 2012; COUTTOLENC; LA ForGIA, 2009).

O Programa de Reestruturação e Contratualização dos Hospitais Filantrópicos no SUS busca, portanto, através de intervenção em três eixos (financiamento, gestão e assistência), mudar a atenção hospitalar nesse segmento do sistema de saúde, visando aos objetivos acima descritos. Cabe a esta pesquisa, diante do exposto, avaliar o programa a partir do eixo do financiamento, descrevendo como este se dá nos estabelecimentos selecionados e as consequências observadas.

\section{Metodologia}

Para avaliar o eixo de financiamento que integra o Programa de Contratualização e Reestruturação dos Hospitais Filantrópicas em dois estabelecimentos de saúde, foi realizada uma pesquisa qualitativa e quantitativa. Os hospitais estudados estão localizados em um município de médio porte de Minas Gerais, com gestão plena do sistema municipal.

Foram selecionados e avaliados documentos (contratos, planos operativos, relatórios, atas de reuniões) e coletados dados quantitativos/financeiros nas bases de dados do Datasus. Foi selecionado como referência para a coleta desses dados quantitativos o intervalo entre 2011 e 2016 para comparar o perfil assistencial, a produção e os valores financeiros que os hospitais receberiam adotando os modelos de contratação antigo (por produção) e atual (através de metas e incentivos).

A coleta de dados também foi realizada através de entrevistas semiestruturadas em profundidade, no ano de 2016, com os administradores dos dois hospitais filantrópicos participantes do programa $(\mathrm{H})$ e com os demais integrantes da comissão 
de acompanhamento: gestor local do SUS (GM) e os representantes do governo estadual (GE), dos municípios da microrregião (GR) e do conselho de saúde (CM), totalizando doze entrevistados. As entrevistas foram gravadas e posteriormente transcritas e analisadas conforme o método de análise de conteúdo. Por meio deste, foi possível identificar o significado que cada entrevistado exterioriza em seu discurso (CHIzzOTTI, 2006).

O roteiro de entrevista foi divido em dois blocos. Primeiro, foram questionadas a formação e a atuação profissional do entrevistado e sua relação com a contratualização. Depois, foram realizadas questões mais focadas nos eixos do programa, em especial o financiamento. A pesquisa documental e a elaboração de relatórios com dados do Ministério da Saúde foram realizadas numa etapa anterior da pesquisa e foram apresentadas aos entrevistados para que estes comentassem em momento oportuno, para que as opiniões iniciais não fossem influenciadas pelos dados. Acredita-se que as respostas para as perguntas previamente elaboradas contribuíram para a explicação das informações e dados previamente levantados e para a apresentação de uma visão mais robusta e avaliativa do programa.

\section{Análise dos resultados}

Uma das principais mudanças trazidas pelo Programa de Reestruturação e Contratualização dos Hospitais Filantrópicos no SUS foi a alteração do método de financiamento. Antes da adesão ao novo tipo de contratação, os hospitais recebiam de acordo com sua produção, ou seja, o valor referente a cada internação, definido pela tabela de procedimentos do SUS. Com a contratualização, os pagamentos mensais passam a ser definidos pela média dos últimos períodos avaliados e inserem-se metas nos eixos da gestão e da assistência que podem impactar no valor a ser recebido. Os procedimentos de alta complexidade, leitos de UTI e os serviços financiados por programas especiais do Ministério da Saúde continuam sendo pagos por produção.

Todo atendimento realizado nos hospitais para o SUS, seja ele ambulatorial ou hospitalar (sem e com internação, respectivamente), deve ser registrado nos sistemas de informação oficiais do Ministério da Saúde, desenvolvidos e acompanhados pelo Datasus. Os procedimentos ambulatoriais são processados no SIA, e os hospitalares, no SIHD. Cada um desses sistemas possui suas particularidades, tendo o SIHD uma complexidade maior. As internações são registradas por completo, com a relação de todos os procedimentos realizados e por quais profissionais, as órteses e próteses eventualmente utilizadas, se houve internação em leito de UTI, além dos dados pessoais e clínicos do paciente e do período que durou a internação. 
Essa informação, contudo, não é utilizada para o pagamento dos serviços, neste momento. Os valores mensais da média complexidade são pagos em parcelas préfixadas, ou seja, independente do que foi realizado no hospital neste mês, o valor que eles receberão já é conhecido previamente e não é alterado em função da produção no curto prazo. Apenas depois de uma avaliação da média, a cada quatro meses, é feita uma revisão dos valores. Os entrevistados foram questionados sobre a efetividade dessa regra contratual e as respostas demonstram algumas limitações na prática.

Nós não conseguimos ir aumentando gradativamente a parcela préfixada porque o valor que recebemos do Ministério da Saúde não permite. Se recebemos $X$, podemos pagar ao hospital no máximo $X$, independente do que eles produzam. (GM1)

Há muitos meses que não temos revisão nos valores das parcelas préfixadas porque a Secretaria de Saúde não analisa nossa série histórica. Estamos congelados nesse valor há muito tempo. (H1T)

Já que não vão nos pagar nada a mais por isso, preferimos deixar na gaveta e apresentar só o que corresponde ao valor da parcela pré-fixada. (H2T)

A estratégia de manter as AlHs na "gaveta", ou seja, sem o processamento e a baixa na Secretaria Municipal de Saúde, é comum nos dois hospitais, serve de barganha para indicar o montante da dívida do governo com eles e para buscar recursos extras junto a outras esferas.

Como visto, o financiamento hospitalar no SUS é mais complexo do que as já complexas regras da Contratualização. A Secretaria Municipal de Saúde repassa aos hospitais o valor que recebem do Fundo Nacional de Saúde, do Governo Federal. Neste valor está incluída a média complexidade e os incentivos. Segundo os representantes dos hospitais, esses valores são insuficientes até mesmo para pagar os custos dos procedimentos realizados, fazendo com que dependam de recursos extras para que a dívida não cresça ainda mais. Dentre as fontes de receita extras citadas pelos administradores hospitalares destacam-se: Pró-hosp (programa desenvolvido pelo Governo Estadual que possui objetivos similares à Contratualização, porém sem o vínculo com a produção de serviços ambulatoriais e hospitalares), receitas de planos de saúde e de internações particulares, emendas parlamentares, programas especiais criados pelos governos municipal, estadual e federal e doações. Durante as perguntas que se desdobraram a partir de um questionamento sobre a saúde financeira dos hospitais, foi recorrente a citação da intervenção de políticos do Poder Legislativo como a principal fonte de recursos extras à Contratualização nos últimos anos. 
Dependemos desses recursos. Os diretores viraram políticos e precisam fazer acordos, bater na porta dos deputados e depois servirem de garoto propaganda deles. (H1S)

É uma troca de favores. Nós precisamos de dinheiro e eles de apoio político e propaganda junto aos eleitores. (H2T)

Quem financia o SUS agora é o Poder Legislativo. Eles são os salvadores da saúde pública. (GE1)

O recurso que vem do deputado é livre. Usamos como precisamos. Não tem meta e nem prestação de contas. (H1S)

A Contratualização e o Pró-hosp tem uma visão de futuro, no que eles querem transformar a saúde pública. As emendas não. Só para tampar buraco e dizerem que estão investindo em saúde. (GE1)

A política de saúde planejada e estruturada para cumprir objetivos de longo prazo está sendo substituída por uma política imediatista e com interesses particulares envolvidos. As intervenções parlamentares são importantes no momento de crise, mas pouco efetivas no longo prazo.

Outra importante fonte de recursos são os planos de saúde. A Tabela 2 apresenta um possível impacto da discrepância entre o financiamento do SUS e o não SUS em termos de leitos disponíveis, demonstrando como a gestão destes pode ser influenciada pelo financiamento:

Tabela 2 - Leitos Hospitalares

CNES - Recursos Físicos - Hospitalar - Leitos de internação SUS

\begin{tabular}{lccccccc} 
Especialidade & $\mathbf{2 0 1 1}$ & $\mathbf{2 0 1 2}$ & $\mathbf{2 0 1 3}$ & $\mathbf{2 0 1 4}$ & $\mathbf{2 0 1 5}$ & $\mathbf{2 0 1 6}$ & $\begin{array}{c}\text { VARIAÇÃO } \\
\text { (entre 2011 e 2016) }\end{array}$ \\
\hline Cirúrgicos & 37 & 37 & 46 & 42 & 42 & 42 & $13,51 \%$ \\
\hline Clínicos & 81 & 81 & 85 & 81 & 81 & 81 & $0,00 \%$ \\
\hline Obstétrico & 12 & 12 & 8 & 8 & 8 & 8 & $-33,33 \%$ \\
\hline Pediátrico & 26 & 26 & 17 & 17 & 17 & 17 & $-34,62 \%$ \\
\hline Total & $\mathbf{1 5 6}$ & $\mathbf{1 5 6}$ & $\mathbf{1 5 6}$ & $\mathbf{1 4 8}$ & $\mathbf{1 4 8}$ & $\mathbf{1 4 8}$ & $\mathbf{- 5 , 1 3 \%}$ \\
\hline
\end{tabular}

CNES - Recursos Físicos - Hospitalar - Leitos de internação Não SUS

\begin{tabular}{lccccccc} 
Especialidade & $\mathbf{2 0 1 1}$ & $\mathbf{2 0 1 2}$ & $\mathbf{2 0 1 3}$ & $\mathbf{2 0 1 4}$ & $\mathbf{2 0 1 5}$ & $\mathbf{2 0 1 6}$ & $\begin{array}{c}\text { VARIAÇÃO } \\
\text { (entre 2011 e 2016) }\end{array}$ \\
\hline Cirúrgicos & 20 & 20 & 21 & 24 & 29 & 29 & $45,00 \%$ \\
\hline Clínicos & 39 & 39 & 35 & 36 & 36 & 35 & $-10,26 \%$ \\
\hline Obstétrico & 6 & 6 & 8 & 8 & 8 & 7 & $16,67 \%$ \\
\hline Pediátrico & 12 & 12 & 12 & 12 & 12 & 12 & $0,00 \%$ \\
\hline Total & $\mathbf{7 7}$ & $\mathbf{7 7}$ & $\mathbf{7 6}$ & $\mathbf{8 0}$ & $\mathbf{8 5}$ & $\mathbf{8 3}$ & $\mathbf{7 , 7 9 \%}$
\end{tabular}




\begin{tabular}{lccccccc}
\hline \multicolumn{8}{c}{ CNES - Recursos Físicos - Hospitalar - Leitos de internação Total } \\
\hline Especialidade & $\mathbf{2 0 1 1}$ & $\mathbf{2 0 1 2}$ & $\mathbf{2 0 1 3}$ & $\mathbf{2 0 1 4}$ & $\mathbf{2 0 1 5}$ & $\mathbf{2 0 1 6}$ & $\begin{array}{c}\text { VARIAÇÃO } \\
\text { (entre 2011 e 2016) }\end{array}$ \\
\hline Cirúrgicos & 57 & 57 & 67 & 66 & 71 & 71 & $24,56 \%$ \\
\hline Clínicos & 120 & 120 & 120 & 117 & 117 & 116 & $-3,33 \%$ \\
\hline Obstétrico & 18 & 18 & 16 & 16 & 16 & 15 & $-16,67 \%$ \\
\hline Pediátrico & 38 & 38 & 29 & 29 & 29 & 29 & $-23,68 \%$ \\
\hline Total & $\mathbf{2 3 3}$ & $\mathbf{2 3 3}$ & $\mathbf{2 3 2}$ & $\mathbf{2 2 8}$ & $\mathbf{2 3 3}$ & $\mathbf{2 3 1}$ & $-\mathbf{0 , 8 6 \%}$
\end{tabular}

Fonte: Ministério da Saúde - Cadastro Nacional dos Estabelecimentos de Saúde do Brasil

Como é possível observar, nos últimos seis anos o número de leitos disponíveis sofreu pouca variação no total. Contudo, houve uma pequena transferência de leitos do SUS para o atendimento de pacientes particulares e de outros convênios. Antes da apresentação desses dados, os entrevistados foram questionados sobre o quantitativo de leitos e sua distribuição, considerando os diferentes tipos de financiamento disponíveis. As respostas foram compatíveis com os dados que tínhamos.

Sim, tivemos de remanejar o quantitativo de leitos do SUS para particular por causa das dificuldades que temos com os pagamentos das internações pelo SUS. (H1T)

A única coisa que podemos fazer para reduzir as AlHs na gaveta é reduzir a oferta de serviços ao SUS (...) Fazemos isso através da redução dos leitos. (H2T)

Acredito que o número de leitos para o SUS diminuiu desde o início, pelo que me lembro. (GE1)

Eles assumem que diminuíram o número de leitos para o SUS e aumentaram para os pacientes de planos de saúde. (GM3)

Como visto, há a tendência e a intenção estratégica de redução dos leitos hospitalares disponíveis ao SUS, reduzindo assim a oferta destes serviços à população local e impactando no eixo da assistência. Além de tentarem limitar o avanço do número de internações sem pagamento, na gaveta, essa estratégia ajuda os hospitais a cumprirem a meta do aumento da taxa de ocupação. Se o número de internações reduzir menos do que o número de leitos disponíveis, a taxa de ocupação se eleva sem qualquer esforço em termos de aumento de oferta de serviços.

Há na Contratualização um financiamento misto, ou seja, a produção de média complexidade é paga em parcelas pré-fixadas, revistas periodicamente e sujeitas à avaliação qualitativa de desempenho, e a produção de alta complexidade é paga por produção, como nos moldes contratuais anteriores. Não se pode falar, portanto, em 
dívidas decorrentes dos serviços de alta complexidade. Os pagamentos estão em dia e nada é represado. Essa discrepância entre os dois tipos de financiamento gera diversos impactos tanto na capacidade instalada quanto na visão dos administrados hospitalares sobre a contratualização.

Ao analisar a base de dados do Cadastro Nacional de Estabelecimentos de Saúde, comparando o perfil dos dois hospitais hoje e há seis anos, percebe-se que os novos serviços implementados e os novos equipamentos adquiridos são direcionados à alta complexidade. Os equipamentos para a média complexidade foram reduzidos e são adquiridos, em sua quase totalidade, para repor os antigos. A Tabela 3 exemplifica a situação exposta:

Tabela 3 - Equipamentos em uso

\begin{tabular}{lccccccc}
\hline \multicolumn{7}{c}{ CNES - Recursos Físicos - Equipamentos - Em Uso } \\
$\begin{array}{l}\text { Equipamento } \\
\text { selecionado }\end{array}$ & 2011 & 2012 & 2013 & 2014 & 2015 & 2016 & $\begin{array}{c}\text { VARIAÇÃO } \\
\text { (entre 2011 e } \\
\text { 2016) }\end{array}$ \\
\hline $\begin{array}{l}\text { Mamógrafo } \\
\text { Raio X }\end{array}$ & 1 & 1 & 2 & 2 & 2 & 2 & $100,00 \%$ \\
\hline $\begin{array}{l}\text { Tomógrafo } \\
\text { Computadorizado }\end{array}$ & 1 & 12 & 7 & 7 & 7 & 7 & $-46,15 \%$ \\
\hline $\begin{array}{l}\text { Ressonância } \\
\text { Magnética }\end{array}$ & 0 & 1 & 1 & 1 & 1 & 1 & $100,00 \%$ \\
\hline $\begin{array}{l}\text { Ultrassom } \\
\text { Total }\end{array}$ & 6 & 4 & 4 & 4 & 4 & 4 & $-33,33 \%$ \\
\hline
\end{tabular}

Fonte: Ministério da Saúde - Cadastro Nacional dos Estabelecimentos de Saúde do Brasil

Como é possível observar nesse período, foram implantados novos equipamentos de tomografia e ressonância magnética, cujos procedimentos de alta complexidade realizados são financiados por produção. As mamografias, apesar de serem de média complexidade, são financiadas pelo Fundo de Ações Estratégicas e Compensação (Faec), também por produção. Já os procedimentos de radiografia e ultrassom são incluídos no teto da média complexidade, pagos de acordo com as regras da contratualização. A redução do número de equipamentos da média complexidade e a consequente redução da oferta desses serviços à população, contudo, pode ser atribuída tanto à tendência e à intenção de busca da que seria a 
melhor forma de financiamento para as instituições quanto pelo próprio incentivo governamental para o investimento na alta complexidade, através de financiamento dos equipamentos, por exemplo. Os representantes dos hospitais não souberam explicar essa mudança no quantitativo e no perfil dos equipamentos utilizados pelas instituições nos últimos anos.

As bases de dados do SIA e do SIH também demonstram crescimento nos últimos anos apenas nos procedimentos de alta complexidade. Os quantitativos totais de média complexidade no município reduziram-se em $46 \%$ em cinco anos, mais de $9 \%$ ao ano, em média, enquanto na alta complexidade o aumento de 2011 para 2015 foi de $21 \%$ e no Faec (Fundo de Ações Estratégicas e Compensação) quase 900\%.

Tabela 4 - Procedimentos Realizados

\begin{tabular}{|c|c|c|c|c|c|c|}
\hline \multicolumn{7}{|c|}{ Quantidade de Procedimentos Realizados - Média Complexidade } \\
\hline Segmento & 2011 & 2012 & 2013 & 2014 & 2015 & $\begin{array}{l}\text { VARIAÇÃO } \\
\text { (entre } 2011 \text { e } \\
\text { 2015) }\end{array}$ \\
\hline Ambulatorial & 100.766 & 26.989 & 37.934 & 62.668 & 51.974 & $-48,42 \%$ \\
\hline Hospitalar & 7.474 & 7.243 & 7.231 & 7.170 & 6.483 & $-13,26 \%$ \\
\hline Total & 108.240 & 34.232 & 45.165 & 69.838 & 58.457 & $-45,99 \%$ \\
\hline \multicolumn{7}{|c|}{ Quantidade de Procedimentos Realizados - Alta Complexidade } \\
\hline Segmento & 2011 & 2012 & 2013 & 2014 & 2015 & $\begin{array}{l}\text { VARIAÇÃO } \\
\text { (entre } 2011 \text { e } \\
\text { 2015) }\end{array}$ \\
\hline Ambulatorial & 4.395 & 2.304 & 4.279 & 6.079 & 5.309 & $20,80 \%$ \\
\hline Hospitalar & 72 & 78 & 65 & 84 & 96 & $33,33 \%$ \\
\hline Total & 4.467 & 2.382 & 4.344 & 6.163 & 5.405 & $21,00 \%$ \\
\hline \multicolumn{7}{|c|}{ Quantidade de Procedimentos Realizados - FAEC } \\
\hline Segmento & 2011 & 2012 & 2013 & 2014 & 2015 & $\begin{array}{l}\text { VARIAÇÃO } \\
\text { (entre } 2011 \text { e } \\
\text { 2015) }\end{array}$ \\
\hline Ambulatorial & 88 & 70 & 942 & 465 & 930 & $956,82 \%$ \\
\hline Hospitalar & 8 & 69 & 230 & 192 & 22 & $175,00 \%$ \\
\hline Total & 96 & 139 & 1.172 & 657 & 952 & $891,67 \%$ \\
\hline
\end{tabular}

Fonte: Ministério da Saúde - SIA/SIH

A maior queda na média complexidade está relacionada aos procedimentos ambulatoriais. Como exposto na Tabela 3, houve uma redução na oferta de procedimentos de radiografia e ultrassom, dois dos serviços de diagnósticos mais utilizados no país. Contudo, ao analisar a queda brusca no número de atendimentos ambulatoriais de média complexidade entre os anos de 2011 e 2012, de 100.766 para 26.989, percebe-se, através dos dados do DATASUS, que a maior parte dessa 
redução se deve à inauguração da primeira e única Unidade de Pronto Atendimento (UPA) do município, em 2011, que desonerou os hospitais de boa parte dos atendimentos de urgência e emergência. Filtrando os dados de acordo com o caráter de atendimento, constata-se que dos 73.777 procedimentos que deixaram de ser realizados de um ano para o outro, 39,21\% (39.510 procedimentos) são relacionados ao atendimento de urgência. Portanto, isolando esse fator (mudança na rede assistencial regional), pode-se dizer que a quantidade de procedimentos ambulatoriais de média complexidade reduziu-se em $15,15 \%$, ficando próxima da queda nos atendimentos hospitalares de média complexidade.

Apesar das considerações apresentadas, as duas tabelas se complementam ao demonstrarem uma tendência dos hospitais em estarem cada vez menos dependentes do teto da média complexidade, incrementando-se os serviços e equipamentos que são remunerados por produção. Esses dados foram expostos aos representantes dos hospitais e não causaram surpresa ou divergência, apesar de nunca terem se deparado com eles, segundo eles.

Eu não sabia disso, mas acho que é isso mesmo. Passamos a ofertar vários exames de alta complexidade que antes não existiam na cidade. (H2T)

Nunca fizemos relatórios disso, mas sei que os valores que recebemos de alta complexidade aumentou bastante nos últimos anos. (H1T)

Nós estamos segurando mesmo o número de procedimentos de média complexidade porque não estamos recebendo por eles. (H2S)

Não sabia que a variação tinha sido tão alta, mas realmente tivemos redução na média complexidade, tanto internação quanto os exames. (H1S)

Outros membros da comissão também comentaram os dados apresentados.

Eu lembro que meu pai fazia as ressonâncias em Belo Horizonte. Agora já mandamos os pacientes para fazer na cidade X. (GR)

Sim, agora temos exames e cirurgias aqui que antes só existiam em cidades grandes. Todo ano abrem novos serviços desses e isso é bom para a população. Não precisam ficar viajando para ter atendimento. (CM2)

Eles colocam novos equipamentos, mas a fila continua enorme. Só facilitou a questão do transporte mesmo. (CM1)

Para esses exames de alta complexidade melhorou sim, mas os exames mais simples estão cada vez mais difíceis de fazer lá. (GE2) 
Além da capacidade instalada, a existência de duas formas paralelas de financiamento a partir do mesmo contrato pode levar os administradores e diretores dos hospitais a pensarem que o pagamento por produção é mais vantajoso do que por médias históricas. Essa dúvida da pesquisa foi apresentada aos entrevistados para identificar uma opinião prévia sobre a contratualização. Esperávamos que, diante das informações e dados colhidos anteriormente, as opiniões dos representantes dos hospitais fossem mais negativas, valorizando o modelo contratual anterior. Essa hipótese confirmou-se nas respostas.

Acho óbvio que o pagamento por produção é melhor. A gente recebe tudo que produz. Não tem represamento. (H2T)

Se pudéssemos escolher agora optaríamos pelo pagamento por produção. A Contratualização não traz vantagem alguma. Só dívidas. (H1T)

Não sei porque ainda estamos com esse contrato. Muito melhor do jeito que era antes. (H1S)

Todos os nossos problemas são por causa dessa forma de contrato. Acho melhor voltarmos para o pagamento por produção. (H2S)

Com exceção dos representantes do governo municipal contratante, não tínhamos expectativas em relação às respostas, devido ao afastamento destes das informações contábeis dos hospitais. De fato, não há consenso entre eles, tendo alguns opinião similar à dos representantes dos hospitais, e outros, opinião divergente. Em relação aos representantes da Secretaria Municipal de Saúde do município sede dos hospitais, por conhecerem as regras, a produção e os valores pagos tanto no modelo contratual anterior como no atual, era esperado que defenderiam uma posição mais próxima das constatações presentes em nossas planilhas. Essa hipótese confirmou-se.

Eu nunca analisei dados financeiros, mas acho a Contratualização pior. Eles recebem menos do que deveriam. (GE2)

Pelas falas dos hospitais esse contrato é péssimo. Só gera problemas, além de ser muito mais difícil de trabalhar com ele. (CM1)

Acho que o contrato atual é bom por exigir metas e melhor qualidade, mas financeiramente acredito ser pior. (GM2)

Já fizemos estudos e mostramos para eles. Com os incentivos o valor recebido na Contratualização é maior do que pagando por produção sem os incentivos. (CM3) 
Sinceramente, eu acho que o que fica represado nem é tão significativo se comparado com o total. Os incentivos cobrem essa diferença e ainda sobra. (CM1)

Eles não são obrigados a permanecerem na Contratualização. Podem pedir para voltar para o tipo de contrato atual, mas não fazem isso. Eles sabem que agora está melhor. $\mathrm{O}$ discurso contrário à contratualização é para justificar os pedidos de mais recursos. (GE1)

Diante do exposto, procurou-se verificar se essa percepção dos entrevistados se confirma, a partir dos dados coletados nas bases de dados do Ministério da Saúde e com as informações de pagamento presentes no Portal da Transparência do município. Por meio da Tabela 5 apresentam-se as simulações, para os dois hospitais em conjunto, dos valores que estes receberiam se o financiamento por todos os serviços ofertados ao SUS fosse por produção, comparando com o modelo contratual atual, em cinco anos:

Tabela 5 - Comparação com e sem a Contratualização

\section{COMPARATIVO PRODUZIDO X PAGO}

2011

Segmento

Produzido Pago Diferença

Ambulatorial $\quad \mathrm{R} \$ 2.601 .843,90$

Hospitalar

$\mathrm{R} \$ \mathbf{8 . 1 9 5 . 1 9 8 , 8 2}$

$\mathrm{R} \$ 14.153 .887,13$

$\mathrm{R} \$ 3.356 .844,41$

Total

$\mathrm{R} \$ 10.797 .042,72$

2012

\begin{tabular}{|c|c|c|c|}
\hline \multirow{2}{*}{ Segmento } & \\
\hline & Produzido & Pago & Diferença \\
\hline Ambulatorial & $\mathrm{R} \$ 1.459 .497,31$ & \multirow{3}{*}{$\mathrm{R} \$ 14.611 .689,12$} & \multirow{3}{*}{$\begin{array}{l}R \$ \\
4.740 .017,53\end{array}$} \\
\hline Hospitalar & $\mathrm{R} \$ 8.412 .174,28$ & & \\
\hline Total & $\mathrm{R} \$ 9.871 .671,59$ & & \\
\hline \multirow{2}{*}{ Segmento } & \multicolumn{3}{|c|}{2013} \\
\hline & Produzido & Pago & Diferença \\
\hline Ambulatorial & $\mathrm{R} \$ 2.134 .795,45$ & \multirow{3}{*}{$\mathrm{R} \$ 14.277 .131,06$} & \multirow{3}{*}{$\begin{array}{l}\mathrm{R} \$ \\
2.995 .288,76\end{array}$} \\
\hline Hospitalar & $\mathrm{R} \$ 9.147 .046,85$ & & \\
\hline Total & $\mathrm{R} \$ 11.281 .842,30$ & & \\
\hline
\end{tabular}




\begin{tabular}{|c|c|c|c|}
\hline \multirow{2}{*}{ Segmento } & \multicolumn{3}{|c|}{2014} \\
\hline & Produzido & Pago & Diferença \\
\hline Ambulatorial & $\mathrm{R} \$ 3.101 .814,87$ & \multirow{3}{*}{$\mathrm{R} \$ 18.024 .829,94$} & \multirow{3}{*}{$\begin{array}{l}\mathrm{R} \$ \\
5.548 .496,42\end{array}$} \\
\hline Hospitalar & $\mathrm{R} \$ 9.374 .518,65$ & & \\
\hline Total & $\mathrm{R} \$ 12.476 .333,52$ & & \\
\hline \multirow{2}{*}{ Segmento } & \multicolumn{3}{|c|}{2015} \\
\hline & Produzido & Pago & Diferença \\
\hline Ambulatorial & $R \$ 2.619 .234,35$ & \multirow{3}{*}{$\mathrm{R} \$ 19.366 .870,62$} & \multirow{3}{*}{$\begin{array}{l}\mathrm{R} \$ \\
8.186 .918,00\end{array}$} \\
\hline Hospitalar & $R \$ 8.560 .718,27$ & & \\
\hline Total & $\mathrm{R} \$ 11.179 .952,62$ & & \\
\hline
\end{tabular}

A Tabela 5 demonstra que os valores recebidos pelos hospitais foram superiores ao produzido em todos os anos, variando de $26 \%$ a maior em 2013 a $73 \%$ a maior em 2015. Esses valores a mais representam, na verdade, incentivos diretamente relacionados à adesão à contratualização. Os administradores dos hospitais, ao terem acesso à tabela após terem expostos suas opiniões pessoais sobre a contratualização, apresentaram justificativas semelhantes para esses resultados.

É porque nessa simulação estão sendo considerados os incentivos. Incentivo não é para pagar os procedimentos. (H2T)

Com os incentivos talvez dê mais do que o pagamento por produção mesmo, mas você não pode misturar as duas coisas. O pagamento da produção atual é menor do que se fosse pagamento por produção. (H2T)

Apesar dos incentivos realmente não terem como objetivo cobrir déficit no pagamento da produção, é importante frisar que eles são pagos apenas para os hospitais contratualizados. Se os hospitais optassem pelo contrato com pagamento por produção, receberiam mais recursos diretamente relacionados a essa produção, mas não teriam os incentivos que hoje em dia são maiores do que a diferença do que deixa de ser pago devido ao teto da parcela pré-fixada. Reafirma-se, portanto, que a simulação apresentada representa valores para as duas realidades (com e sem a Contratualização), independente dos argumentos de finalidade dos incentivos. No final, esses seriam os valores disponíveis para o financiamento dos serviços hospitalares. 


\section{Conclusão}

A partir dos resultados desta pesquisa, é possível chegar a algumas constatações. A principal é que o modelo contratual adotado tem impactado na gestão dos serviços disponibilizados pelos hospitais. Houve uma transferência de investimento da média para a alta complexidade, reduzindo a oferta de serviços à população e alterando o perfil assistencial na rede de atenção local por iniciativa dos hospitais, sem negociação com os demais membros da comissão de acompanhamento do contrato. A manutenção de duas formas de pagamento de forma simultânea - parte por produção (alta complexidade e Faec) e parte dentro de um teto fixo (média complexidade) - pode ter criado a visão de que a primeira seria superior à segunda. A descrição das formas de financiamento e as opiniões dos entrevistados demonstram como o pagamento através de parcela fixa preestabelecida gera alguns transtornos, como as AlHs na gaveta e desestímulos ao incremento nos serviços de média complexidade. Se o valor a receber é limitado, os hospitais tendem a cumprir apenas o acordado. Produzir mais geraria prejuízos para os hospitais, os quais passariam a assumir custos não financiados pelo SUS. Contudo, essas constatações partem do enfoque dado nesta pesquisa e do ponto de vista dos entrevistados. Pesquisas complementares podem analisar o impacto das demais políticas públicas de saúde dos governos estadual e federal na gestão dos leitos, serviços e equipamentos. Não se pode isolar os efeitos da Contratualização sobre as mudanças constatadas, mas podemos perceber como o programa induz a elas.

Um ponto que não foi discutido nas entrevistas, mas que cabe observar nesta discussão de financiamento, diz respeito ao benefício que os hospitais filantrópicos sem fins lucrativos possuem frente às suas obrigações tributárias. O Certificado de Entidade Beneficente de Assistência Social (Cebas), emitido pelo Ministério da Saúde, permite que esses estabelecimentos fiquem isentos do pagamento da contribuição patronal para a Previdência Social. Participar do SUS, portanto, não se resume às regras contratuais e ao financiamento acordado. Há outras vantagens indiretas, além de ser compatível com sua própria missão institucional (filantropia sem fins lucrativos).

Em síntese, percebe-se que há um discurso inflamado dos representantes dos hospitais contra a metodologia de pagamento adotada neste modelo de contratação de serviços hospitalares, impactando até mesmo nas tomadas de decisão sobre quais procedimentos ofertar ou não aos cidadãos. Ao se analisar os dados financeiros, entretanto, observa-se que o problema do financiamento não é provocado pela Contratualização. As dificuldades financeiras dos hospitais ainda persistem, principalmente devido à defasagem da tabela de procedimentos do SUS, mas algum avanço está provado que houve nesse processo. Os valores recebidos 
pelos hospitais estão superiores no modelo contratual atual se comparados com o modelo anterior (pagamento por produção). Contudo, considerando que era objetivo do Programa de Reestruturação e Contratualização dos Hospitais Filantrópicos no SUS solucionar o problema do subfinanciamento da atenção hospitalar, não se pode afirmar que houve sucesso na iniciativa do Ministério da Saúde. Ao se analisar as falas dos administradores hospitalares e suas planilhas de déficit, constata-se que essas ações se mostraram insuficientes.

Por fim, considerando o objetivo desta pesquisa de identificar, sob a ótica dos implementadores, os impactos, avanços, lacunas e problemas no eixo do financiamento do programa, cruzando os depoimentos com os dados coletados nas bases do Ministério da Saúde e nos demais documentos analisados, pode-se apresentar como principais resultados: (i) houve ampla utilização dos contratos de metas, o que estimularia a melhoria da gestão e da assistência; (ii) observou-se o incremento do financiamento, mas de forma ainda insatisfatória para sanar os problemas financeiros das instituições; (iii) os limites orçamentários do governo local ainda impedem a execução integral do contrato, gerando o represamento; e (iv) a existência conjunta de dois tipos de financiamento estimula os hospitais a priorizarem determinados tipos de atendimento (alta complexidade, FAEC e planos de saúde) em detrimento de outros (média complexidade).

\section{Referências bibliográficas}

AlmeidA, B. C.; PAULA, S. L. O papel da avaliação de políticas públicas no contexto dos governos locais. Planejamento e Políticas Públicas, n. 42, jan./jun. 2014.

ARRETCHE, M. Tendências no estudo sobre avaliação. In: Rıco, E. M. (Org.). Avaliação de políticas sociais: uma questão em debate. 3. ed. São Paulo: Cortez, 2001.

BARbosA, N. B.; EliAS, P. E. M. As organizações sociais de saúde como forma de gestão público/privado. Ciênc. saúde coletiva, Rio de Janeiro, v. 15, n. 5, p. 24832495, ago. 2010.

BARBosA, P. R. et al. Caracterização assistencial de hospitais filantrópicos no Brasil. Rev. Saúde Pública, São Paulo, v. 38, n. 6, p. 811-818, dez. 2004.

BARBOSA, P. R. et al. O setor hospitalar filantrópico e alguns desafios para as políticas públicas em saúde. Revista de Administração Pública, Rio de Janeiro, v. 37, n. 2, p. 265-283, mar./abr. 2003.

BRASIL. Ministério da Saúde, Portaria GM/MS no 1.721, de 21 de setembro de 2005. Cria o Programa de Reestruturação e Contratualização dos Hospitais Filantrópicos no Sistema Único de Saúde - SUS. Disponível em: <http://bvsms.saude.gov.br/bvs/ saudelegis/gm/2005/prt1721_15_09_2005.html>. Acesso em: 8 abr. 2016.

BRASIL. Ministério da Saúde, Portaria GM/MS no 3.390, de 30 de dezembro de 2013a. Institui a Política Nacional de Atenção Hospitalar (PNHOSP) no âmbito do 
Sistema Único de Saúde (SUS), estabelecendo-se as diretrizes para a organização do componente hospitalar da Rede de Atenção à Saúde (RAS). Disponível em: <http:// bvsms.saude.gov.br/bvs/saudelegis/gm/2013/prt3390_30_12_2013.html>. Acesso em: 8 abr. 2016.

BRASIL. Ministério da Saúde, Portaria GM/MS no 3.410, de 30 de dezembro de 2013b. Estabelece as diretrizes para a contratualização de hospitais no âmbito do Sistema Único de Saúde (SUS) em consonância com a Política Nacional de Atenção Hospitalar (PNHOSP). Disponível em: <http://bvsms.saude.gov.br/bvs/saudelegis/ gm/2014/prt3410_30_12_2013.html>. Acesso em: 8 abr. 2016.

CAvalcante, A. P. Contratualização da Rede Hospitalar SUS. In: Congresso FEHOSP, 21, 2012, Campinas. Anais... São Paulo, FEHOSP, 2012. Disponível em: <http://www. eventosfehosp.com.br/galeria2012/> Acesso em: 10 maio 2015.

CHIzzottı, A. Pesquisa em ciências humanas e sociais. 8. ed. São Paulo: Cortez, 2006.

ConAss. Nota Técnica 24/2013: Política Nacional de Atenção Hospitalar. 2013. Disponível em <http://www.conass.org.br/Notas\%20t\%C3\%A9cnicas\%202013/ NT\%2024-2013\%20PNOHOSP\%20vf.pdf>. Acesso em: 10 maio 2015.

COSTA, F. L. da; CASTANHAR, J. C. Avaliação de programas públicos: desafios conceituais e metodológicos. Revista de Administração Pública, Rio de Janeiro, v. 37, n. 5, p. 962-969, set./out. 2003.

Couttolenc, B. F.; LA ForgiA, G. M. Desempenho hospitalar no Brasil: em busca da excelência. São Paulo: Singular, 2009.

Deubel, A. N. R. Perspectivas teóricas para el análisis de las políticas públicas: ¿de la razón científica al arte retórico? Estudios Políticos. Medellin, n. 33, p. 67-91, jul./ dic., 2008.

FonsECA, F. Dimensões críticas das políticas públicas. Cadernos EBAPE.BR, Rio de Janeiro, v. 11, n. 3, p. 402-418, set./nov. 2013.

FREY, K. Políticas públicas: um debate conceitual e reflexões referentes à prática da análise de políticas públicas no Brasil. Revista Planejamento e Políticas Públicas. Brasília, n. 21, p. 211-259, jun. 2000.

Godoy, A. S. Estudo de caso qualitativo. In: Godol, C. K.; BANDEIRA-DE-Mello, R.; SIlvA, A. B. Pesquisa Qualitativa em Estudos Organizacionais. São Paulo: Saraiva, 2006, p.115-146.

LIMA, S. M. L.; RIVERA, F. J. U. A contratualização nos hospitais de ensino no Sistema Único de Saúde brasileiro. Ciênc. saúde coletiva, Rio de Janeiro, v. 17, n. 9, p. $2507-$ 2521, set. 2012.

MATTOS, R. A. de; BAPTISTA, T. W. de F. A ideia do ciclo na análise de políticas públicas. In: _. Caminhos para análise das políticas públicas de saúde. Porto Alegre: Rede UNIDA, 2015, p. 221-272.

MESTRINER, M. L. O Estado entre a filantropia e a assistência social. 3. ed. São Paulo: Cortez Editora, 2008.

QUINTELLA, J. E. de V (Coord.). Estudos de contratualização de hospitais no âmbito do SUS. Rio de Janeiro: Fundação Getúlio Vargas, 2007. 
Sılva, H. M. A política pública de saúde no Brasil: dilemas e desafios para a institucionalização do SUS. 1996. 132 p. Dissertação (Mestrado em Administração Pública) - Fundação Getúlio Vargas, Rio de Janeiro, 1996.

SILVA, M. O. S. Avaliação de políticas públicas e programas sociais: aspectos conceituais e metodológicos. In: SILVA, Maria O. S. (Org.). Avaliação de políticas públicas e programas sociais: teoria e prática. São Paulo: Veras, 2001.

SOUZA, C. Políticas Públicas: uma revisão de literatura. Sociologias, Porto Alegre, n. 16, p. 20-45, dez. 2006.

\section{César Augusto Neves}

Mestre em Administração Pública pela Universidade Federal de Lavras (UFLA). Atualmente é tutor a distância do curso de Graduação em Administração Pública da Universidade Federal de São João Del-Rei e servidor do Instituto Federal de Educação, Ciência e Tecnologia do Sudeste de Minas Gerais, Campus São João Del-Rei. Contato: cesar.neves@ifsudestemg.edu.br

\section{Patrícia Aparecida Ferreira}

Doutora em Administração pela Universidade Federal de Lavras (UFLA).Atualmente é professora do Departamento de Administração e Economia daUFLA e tutora do Programa de Educação Tutorial (PET) Administração daUFLA. Está vinculada ao Programa de Pós-Graduação em Administração Pública (PPGAP). Contato: paf@dae.ufla.br

\section{Dany Flávio Tonelli}

Doutor em Administração pela Universidade de Lavras (UFLA). Atualmente é professor adjunto do Departamento de Administração e Economia (DAE/UFLA) e nos cursos de graduação em Administração Pública. Está vinculado ao Programa de Pós-Graduação em Administração Pública (PPGAP-UFLA) e colabora no Programa de Pósgraduação em Administração e no Programa de Pós-graduação em Desenvolvimento e Extensão. Também atua como pró-reitor adjunto na Pró-reitoria de Extensão e Cultura (PROEC) e como responsável pela Coordenadoria de Desenvolvimento Tecnológico e Social (CODETS-PROEC). Contato: danytonelli@gmail.com 